\title{
Epidemiological Studies on Physical, Chemical, Zoonotic and Psychological Hazards among Veterinarians
}

\author{
Tanuja Parmar", A.K. Upadhyay, Maansi and Richa Rautela \\ Department of Veterinary Public Health and Epidemiology, College of Veterinary and Animal Sciences, GBPUAT, \\ Pantnagar, INDIA \\ *Corresponding author: T Parmar; E-mail: tanujaparmar277@gmail.com
}

Received: 07 Dec., 2020

Revised: 02 Jan., 2021

Accepted: 09 Jan., 2021

\begin{abstract}
The veterinary profession is complex and the demand of this profession expose veterinarians to various risks like traumatic injuries, zoonotic diseases and mental health hazards. This study reports physical, chemical, biological, psychological health hazards and awareness relevant to Indian veterinarians as obtained by self administered questionnaire. As many as 392 veterinarians were surveyed. Physical injuries reported were Bite (31.8\%), scratch (65.1\%), kick (62.8\%), horn wound (14\%), needle prick (89.2\%), fracture (3.8\%) and injuries due to falling/ lifting animals/ moving heavy equipments (61.3\%). Majority of veterinarians experienced some form of allergy. Incidence of skin irritation was highest among (50.2\%) veterinarians. Ringworm (13.5\%) and fungal infection (26.5\%) were most common zoonotic infection. Low level stress was reported in $45 \%$ of participants, $34 \%$ had moderate and $21 \%$ felt high level of psychological stress. The proportion of participants using protective equipments include $60 \%$ gloves, $1.1 \%$ goggles, and $39.8 \%$ apron The study showed that $171(43.6 \%), 122(31.1 \%)$, $67(17.1 \%), 32(8.2 \%)$ veterinarians followed deworming at 6 month, 1 year, 2 year and more than 2 year intervals respectively. The awareness levels concerning occupational hazards among the veterinary health professionals was near optimal but the need was felt to implement efforts aimed at addressing deterrence of occupational hazards.
\end{abstract}

\section{HIGHLIGHTS}

(0 Veterinarians are on risk for various health hazards during clinical practice.

( Majority of veterinarians experienced some form of allergy.

Keywords: Awareness, Epidemiological study, Hazard, Veterinarian, Zoonotic

Veterinary profession is one such occupation that primarily aims to protect the health of animals (Bonini et al., 2016). A veterinarian is a person who interacts with a range of animals and thus in process carries the greatest risk of occupational hazards (Epp and Waldner, 2012). This veterinary profession is physically demanding and related to an increased risk of accidents, ranging from moderate to high, and the development of musculoskeletal disorders (Mishra and Palkhade, 2020). Clinically practicing veterinarians are exposed to zoonotic diseases and occupational hazards (Rood and Pate, 2019). Physical and mental illnesses or stress also serve as the potential risks to humans (Fritschi et al., 2008). Chemical hazards include contact with antineoplastic drugs, hormones, pesticides, and anesthetic gases (Joni et al., 2017). The hazardous effect of chemicals such as chromium salts, nickel salts, acetamide and propanol used in veterinary practice include teratogenicity, corrosiveness, carcinogenicity, allergic reaction and lung damage. Biological risk is prevalent in all work activities where there is possibility of exposure to pathogenic microorganisms. Human brucellosis is major occupational hazard affecting dairy farmers, veterinarians, veterinary assistants and veterinary pharmacists

How to cite this article: Parmar, T., Upadhyay, A.K., Maansi and Rautela, R. (2021). Epidemiological studies on physical, chemical, zoonotic and psychological hazards among veterinarians. J. Anim. Res., 11(1): 131-136. Source of Support: None; Conflict of Interest: None क्) 
(Yohannes and Gill, 2011). The main route of transmission of disease include needle prick injuries while vaccinating female calves, and contact with infected excretions and secretions of animals (Leggat et al., 2009; Kutlu et al., 2014). In addition to zoonotic diseases, veterinarians are also prone to develop allergies, sensitisation, allergic rhinitis, conjunctivitis, asthma and dermatitis (Samadi et al., 2012).

The common sources of allergens are hair, dander, saliva and serum, in rabbits and rodents, main source of allergens is urine (Moghtaderi et al., 2014). Lack of awareness regarding the hazards is leading more veterinarians at risk and in turn succumbing to various hazards. The risk factors once removed will prevent many veterinarians facing the hazards.

\section{MATERIALS AND METHODS}

The study was a descriptive cross-sectional type of study in design and it occupied only qualitative and quantitative data collection methods. The data were collected by using a self-prepared questionnaire from thirteen districts of Uttarakhand and some places of Uttar Pradesh and Punjab states. The period of study was August 2017 to February 2018. Data were collected through personal interview with veterinarians at their hospitals, by distributing questionnaire to government V.O.'s during their monthly meetings and posted to various veterinary hospitals.

The study population included field veterinarians of Uttarakhand state and academic veterinarians belonging to clinical departments of different institutions of Uttarakhand, Punjab and Uttar Pradesh states. The data collected from questionnaire were identified by numbers, coded numerically and entered into the MS Excel program and percentage frequencies were calculated on 40 questions based on the demographics and occupational hazards and preventive measures taken. Occupational hazards were further categorized into physical hazards, radiation hazard and safety, chemical hazards, zoonotic hazards and psychological hazards. Details of all these occupational hazards and preventive measures applied by veterinarians were categorized into different tables to present and evaluate information concerning different kind of attributes.

\section{RESULTS AND DISCUSSION}

\section{Background Characteristics of Respondents}

Out of total 1000 questionnaire only 400 responses were achieved. Out of 400 responses, 8 were excluded from further analysis on account of unfilled, not completely filled. Field veterinarians were prompt (61.8\%) compared to veterinarians in academics (38.2\%). Moreover, maximum respondents were having 5 years' service experience followed by 6-10 years and least having more than 20 years veterinary practice.

\section{Hazards}

\section{Physical injuries}

Various studies on veterinary profession have revealed that veterinary work is physically challenging and poses a raised risk of severe injuries or trauma. Majority of veterinarians reported some sort of injuries within last five year. Out of total 392 respondents, 5.1\% (20) reported no injury, 47.5\% (186) respondents had 1-5 injuries, $32.1 \%$ (126) encountered 5-10 injuries and 15.3\% (60) veterinarians had more than 10 injuries during last 5 years. From the analysis of survey we can avow that physical injuries remains one of the main risk factor for veterinarians (Bonini et al., 2016).

Present study explain needle prick injuries are frequent in the veterinary (Table 1), this is found to be in alignment with the work of Fowler et al. (2016). Needle stick injuries may involve the risk of self-injecting drugs and other harmful substances and the primary method to diminish needle stick injuries is to keep away from recapping needles or at the very least use 'one handed scooping technique' to recap (Weese and Jack, 2008). Apart from needle prick injury, veterinarians were also injured by bite, scratch, kick, horn wound, fracture and injuries due to falling while lifting or restraining animals (Table 1). The ergonomic injuries have been acknowledged as physical hazards with recurring task and manual handling burden through lifting and restraining animals contributing too many physical problems among veterinarians (Moore et al., 1993). 
Table 1: Details of different kinds of physical injuries among veterinarians

\begin{tabular}{lcccc}
\hline \multirow{2}{*}{ Type of Injury } & \multicolumn{2}{c}{ Veterinarian injured } & Veterinarian took treatment for injuries \\
\cline { 2 - 5 } & Frequency & Percentage & Frequency & Percentage \\
\hline Animal bite & 125 & $31.8 \%$ & 120 & $96 \%$ \\
Scratch & 255 & $65.1 \%$ & 94 & $36.8 \%$ \\
Kick & 246 & $62.8 \%$ & 43 & $17.4 \%$ \\
Horn wound & 55 & $14 \%$ & 31 & $56.3 \%$ \\
Fracture & 15 & $3.8 \%$ & 15 & $100 \%$ \\
Needle prick & 350 & $89.2 \%$ & 28 & $8 \%$ \\
Injuries due to falling while lifting & 241 & $61.3 \%$ & 143 & $59.3 \%$ \\
or restraining animals & & & &
\end{tabular}

\section{Radiation hazards}

The questionnaire also focused on radiological hazards and preventive measures taken for protection from harmful radiations in veterinary practices (Table 2 ).

Table 2: Veterinarians using protective gears while taking X-rays

\begin{tabular}{lcc}
\hline Attributes & Frequency & Percentage \\
\hline $\begin{array}{l}\text { Total no. of veterinarians taking } \\
\text { x-ray }\end{array}$ & 75 & $19.1 \%(75 / 392)$ \\
$\begin{array}{l}\text { No. of veterinarians using lead } \\
\text { gloves }\end{array}$ & 46 & $61.3 \%(46 / 75)$ \\
$\begin{array}{l}\text { No. of veterinarians using lead } \\
\text { apron }\end{array}$ & 65 & $86.7 \%(65 / 75)$ \\
$\begin{array}{l}\text { No. of veterinarians using lead } \\
\text { sleeves }\end{array}$ & 7 & $9.3 \%(7 / 75)$ \\
$\begin{array}{l}\text { No. of veterinarians using } \\
\text { protective glasses }\end{array}$ & 25 & $33.3 \%(25 / 75)$ \\
$\begin{array}{l}\text { No. of veterinarians using personal } \\
\text { monitor }\end{array}$ & 38 & $50.6 \%(38 / 75)$ \\
\hline
\end{tabular}

The dose of radiation depends on the numbers of $x$-ray taken by the person, type of machine and setting, involvement of veterinarian in physical restraining of animals and protective devices used by the person (Shirangi et al., 2007). The low proportion of veterinarians $19.1 \%$, taking $\mathrm{x}$-ray is not consistent with an Australian study where 79\% practicing veterinarians used radiography as diagnostic tool (Shirangi et al., 2007). The reason for this variance may be unavailability of x-ray machines in government veterinary hospitals in India especially Uttrakhand. The results regarding using protective gears by veterinarians while performing $\mathrm{x}$-rays revealed that $86.7 \%$ were using lead apron but other protective gears like lead gloves, personal monitor, protective glasses and lead sleeves were not common (Table 2), this proportion is nearly similar to those reported by Jacobson and Farowe (1964); Shirangi et al. (2007).

\section{Chemical hazards}

The common chemicals handled by veterinarians include drugs, disinfectants, antiseptics, pesticides etc (Shirangi et al., 2007). Responses on chemical hazard linked sickness revealed that $47.7 \%$ (187) veterinarians were using antineoplastic agents to treat animals and out of 187 individuals, $2.1 \%$ (4) veterinarian accidently injected drugs to themselves. None reported any adverse effect due to self-injection. Adverse effects of disinfectant were reported by $8 \%$ (32) veterinarians. Adverse effects like headache, nausea, skin irritation etc. due to pesticides reported by $0.7 \%$ (3) veterinarians. Allergy due to latex gloves causing itching, skin rashes, skin irritation was reported in $10 \%$ (41) veterinarians. Chemical risk seems to be less pertinent than physical and biological risks but the threats from chemicals and drugs cannot be overlooked and the literature advocated the relevance of these threats (Fritschi, 2008).

\section{Zoonotic hazards}

Veterinarians confront various microbial hazards including viral, bacterial, fungal and parasitic infection acquired from animal contact (Table 3).

Ringworm and other fungal infection are most common zoonotic infection among veterinarians (Table 3), Epp and Waldner (2012) also reported similar result in their study among veterinarian of Western Canada. 
The Influenza virus was reported in $78(19.8 \%)$ veterinarians (Table 3) but there is no report of influenza in veterinarian except for $11 \%$ seroprevalence of swine influenza virus among veterinary students (Woods et al., 1981).

Table 3: Veterinarians contracted various zoonotic diseases while dealing animals

\begin{tabular}{lcc}
\hline Attributes & Frequency & Percentage \\
\hline Ringworm & 53 & $13.5 \%$ \\
Other fungal infections & 104 & $26.5 \%$ \\
Scabies & 20 & $5 \%$ \\
Toxoplasmosis & 2 & $0.5 \%$ \\
Other parasitic infections & 37 & $9.5 \%$ \\
Amoebiosis & 20 & $5 \%$ \\
Tuberculosis & 2 & $0.5 \%$ \\
Brucellosis & 0 & $0 \%$ \\
Staphylococcosis & 0 & $0 \%$ \\
Salmonellosis & 0 & $0 \%$ \\
Influenza & 78 & $19.8 \%$ \\
\hline
\end{tabular}

Among bacterial zoonotic infection, tuberculosis was in 2 $(0.5 \%)$ veterinarians but in a study conducted by Khattak et al. (2016) in Pakistan revealed that 0 veterinarians and 4 abattoir workers were tested positive for $M$. bovis. In our study there is no report of Brucellosis, Salmonellosis and Staphylococcosis (Table 3) but Mudaliar et al. (2003); Shome et al. (2017) carried out a survey among veterinary workers in Delhi and Karnataka and reported seropositive cases as high as $27.7 \%$ and $7.02 \%$ respectively. Study conducted on veterinary students and doctors in the Netherlands revealed a lower MRSA carriage rate (Wulf et al., 2006). Various strains of $S$. aureous are responsible for food poisoning (Gaurav et al., 2019).

The presence of toxoplasmosis $2(0.5 \%)$ was lower than as reported by Rosypal et al. (2015) which was $5.6 \%$ in veterinary student. Amoebiosis and scabies in veterinarian were $20(5 \%)$ while other parasitic infection was $37(9.5 \%)$. Our findings are suggestive of a low level of zoonotic diseases being rampant in the sampled population. Possible explanation for this could be, lack of proper medical checkup, under- reporting of zoonotic diseases.

\section{Psychological hazards}

Work overload, exhaustion due to handling with animals, dealing and satisfying animal's owner, going to visit patients at their places etc. all these lead to mental stress and loss of working days. Low level of stress was shown by 137 (45\%), moderate level by 104 (34\%) and high level of stress was reported by 64 (21\%) veterinarians. The results of the study are consistent with Fowler et al. (2016) they reported recent feelings of depression in 204 $(25 \%)$ respondents.

\section{Preventive health measures taken by veterinarians}

Protective equipments used by participants in survey include gloves by $60 \%$, goggles by $1.1 \%$ and apron by $39.8 \%$. However, $36.7 \%$ (134) participants did not use any of the protective gear during practices. All participants washed their hands properly after checking patients, similarly Aluko et al. (2016) showed that 100\% health care worker followed effective hand washing before and after every clinical practice.

\section{Veterinarians having vaccination}

Lack of prophylactic vaccination against zoonotic diseases ranked second most important constraint in dealing with life savings from zoonoses (Landge et al., 2016). The study revealed that veterinarians have been vaccinated against diseases like Tetanus, Rabies and Measles. The 89\% (350) participants were vaccinated against Tetanus, 66.3\% (260) against Rabies and 81\% (318) against Measles in their life time. The findings are comparable with the number of zoo veterinarians having vaccinations in Australia against Tetanus 95\%, Rabies 70\% and Measles 85\% (Jeyaretnam, 2003).

\section{Veterinarians following routine deworming}

The study showed that 171(43.6\%), 122 (31.1\%), 67 (17.1\%), $32(8.2 \%)$ veterinarians followed deworming at 6 month, 1 year, 2 year and more than 2 year intervals respectively. Nigam and Srivastav (2011) analyzed the details of deworming practiced by the Indian wildlife professionals and it was inferred that only $40.7 \%$ reported carrying out deworming in the last 6 months, $22.2 \%$ in the last 1 year and $12.9 \%$ had done it once in the last two 
years. $24.1 \%$ of the respondents did not follow routine deworming.

\section{CONCLUSION}

In conclusion, the physical injuries were most prevalent among veterinarians. The awareness level concerning occupational hazards among the veterinary health professionals was near optimal but the need was felt to implement efforts aimed at addressing deterrence of occupational hazards by developing and executing improved safe handling practices and safety measures. There are several limitations of this study. The study design did not included serological testing of veterinarians to detect the prevalence zoonotic diseases. These findings are a preparatory point for further investigation into prevention of workplace hazards and a motivation for targeted injury prevention measures that could be instituted by individuals, practices, and veterinary governing bodies.

\section{REFERENCES}

Aluko, O.O., Adebayo, A.E., Adebisi, T.F., Ewegbemi, M.K., Abidoye, A.T. and Popoola, B.F. 2016. Knowledge, attitudes and perceptions of occupational hazards and safety practices in Nigerian healthcare workers. BMC Res. Notes., 9(1): 71.

Bonini, S., Buonacucina, A., Selis, L., Peli, A., Mutti, A. and Corradi, M. 2016. Occupational Hazards in Veterinarians: An Updating. J. Vet. Sci. Technol., 7: 317.

Epp, T. and Waldner, C. 2012. Occupational health hazards in veterinary medicine: Physical, psychological and chemical hazards. Can. Vet. J., 53(2): 151-157.

Fowler, H.N., Holzbauer, S.M., Smith, K.E. and Scheftel, J.M. 2016. Survey of occupational hazards in Minnesota veterinary practices in 2012. J. Am. Vet. Med. Assoc., 248(2): 207-218.

Fritschi, L., Shirangi, A., Robertson, I.D. and Day, L.M. 2008. Trends in exposure of veterinarians to physical and chemical hazards and use of protection practices. Int. Arch. Occup. Environ. Health., 81: 371-378.

Gaurav, K., Nathiya, P., Bhati, T. and Kataria, A.K. 2019. Detection of Enterotoxin Genes (seg, seh and sei) in Staphylococcus aureus Milk Isolates from Cow with Subclinical Mastitis. J. Anim. Res., 9(2): 275- 280.

Jacobson, G. and Van Farowe, D.E. 1964. Dental radiological health program. J. Mich. State. Dent. Ass., 46.

Jeyaretnam, J.S. 2003. Occupational hazards and radiation safety in veterinary practice including zoo veterinary practice in Australia. https://ro.ecu.edu.au/theses/1306 Dated: 04.12.2020
Joni, M., Scheftel, Brigid, L., Elchos, Carol, S., Rubin, and John A. Decker. 2017. Review of hazards to female reproductive health in veterinary practice. J. Am. Vet. Med. Assoc., 250(8): 862-872.

Khattak, Mushtaq, M.H., Ahmad, M.U.D., Khan, M.S. and Haider, J. 2016. Zoonotic tuberculosis in occupationally exposed groups in Pakistan. J. Occup. Med., 66(5): 371-376.

Kutlu, M., Ergonul, O., Sayin- Kutlu, S., Guven, T., and Usttun, C. 2014. Risk factors for occupational brucellosis among veterinary personnel in Turkey. Prev. Vet. Med., 117: 52-58.

Landge, S., Tripathi, H., Agarwal, R.K. and Banthiya, V. 2016. Knowledge Level of Veterinarians about Occupational Health Hazards and the Constraints Felt by them for Safe and Hazard Free Working Conditions. J. Vet. Pub. Hlth., 9(2): 75-82.

Leggat, P., Smith, D. and Speare, R. 2009. Hand dermatitis among veterinarians from Queensland, Australia. Contact Dermatitis., 60: 336-338.

Mishra, S. and Palkhade, R. 2020. Risk factors and prevalence of work-related injuries and accidents among veterinarians in India. Vet. World., 13(11): 2555-2564.

Moghtaderi, M., Farjadian, S., and Abbaszadeh Hasiri, M. 2014. Animal allergen sensitization in veterinarians and laboratory animal workers. J. Occup. Med., 64(7): 516-520.

Moore, R.M.Jr., Davis, Y.M., and Kaczmarek R.G. 1993. An overview of occupational hazards among veterinarians, with particular reference to pregnant women. Am. Ind. Hyg. Assoc. J., 54: 113-120.

Mudaliar, S., Bhore, A. and Pandit, D. 2003. Detection of antibodies to Brucella abortus in animal handlers. Ind. J. Med. Sci., 57: 181-186.

Nigam, P. and Srivastav, A. 2011. Assessing occupational hazards among Indian wildlife Assessing occupational hazards among Indian wildlife health professionals. Vet. Arhiv., 81: 731-741.

Rood, K.A. and Pate, M.L. 2019. Assessment of Musculoskeletal Injuries Associated with Palpation, Infection Control Practices, and Zoonotic Disease Risks among Utah Clinical Veterinarians. J. Agromedicine., 24(1): 35-45.

Rosypal, A.C., Houk, A.E., Zajac, A.M. and Lindsay D.S. 2015. Prevalence of IgG antibodies to Toxoplasma gondii in veterinary and undergraduate students at virginia tech, Blacksburg, Virginia. Zoonoses. Public. Hlth., 62: 553-556.

Samadi, S., Spithoven, J., Jamshidifard, A.R., Berends, B.R., Lipman, L., Heederik, D.J., and Wouters, I.M. 2012. Allergy among veterinary medicine students in The Netherlands. Occup. Environ. Med., 69(1): 48-55.

Shirangi, A., Fritchi, C. and Holman. D.J. 2007. Prevalence of occupational exposure and protective practices in Australian female veterinarians. Aus. Vet. J., 85: 32-38. 
Shome, R., Kalleshamurthy, T., Shankaranarayana, P.B., Giribattanvar, P., Chandrashekar, N., Mohandoss, N. and Rahman, H. 2017. Prevalence and risk factors of brucellosis among veterinary health care professionals. Pathog. Glob. Health., 111(5): 234-239.

Weese, J.S., and Jack, D.C. 2008. Needlestick injuries in veterinary medicine. Can. Vet. J., 49(8): 780.

Woods, G.T., Schnurrenberger P.R., Martin R.J. and Tompkins W.A.F. 1981. Swine influenza-virus in swine and man in Illinois. J. Occup. Environ. Med., 23: 263-267.68.
Wulf, M., Van Nes, A., Eikelenboom-Boskamp, A., de Vries, J., Melchers, W., Klaassen, C. and Voss, A. 2006. Methicillinresistant Staphylococcus aureus in veterinary doctors and students, the Netherlands. Emerg. Infect. Dis., 12:1939-1941.

Yohannes, M. and Gill, J.P.S. 2011. Seroepidemiological survey of human brucellosis in and around Ludhiana, India. Emerg. Health Threats J., 4: 7361. 